\section{Delivery Systems for Intravenous Nitroglycerin}

The indications for administration of intravenous nitroglycerin (IV NTG) have broadened considerably. Anaesthesiologists and intensivists may wish to utilize the venous, arterial, or coronary vasodilator properties of IV NTG for the treatment of myocasdial infarction, myocardial ischaemia, congestive heart failure, hypertension, or for the induction of deliberate hypotension. ${ }^{1}$ In addition to pharmacokinetic and pharmacodynamic variables influencing the dose-response relationship for IV NTG, the delivery systcm uscd to administer NTG may substantially influence the actual dose of NTG administered at a given concentration and infusion rate. ${ }^{2}$ Unless an appropriate delivery system is used to administer IV NTG, the clinical response will be unpredictable and will vary substantially with time. Significant quantities of NTG are adsorbed to the surface, and dissolved in the matrix, of polyvinyl chloride (PVC) plastic, the major constituent of most transparent and flexible intravenous fluid containers and tubing. ${ }^{3}$ The presence of PVC in any portion of an NTG delivery system will result in administration of reduced concentrations of NTC. ${ }^{4}$

The magnitude and time course of fluctuations in administered NTG concentration will depend upon several variables, including NTG concentration, the surface-to-volume ratio of the PVC container or tubing, and the infusion flow rate. ${ }^{5}$ If NTG is administered from a glass container through a PVC infusion set, the administered concentration typically decreases by $50-80$ per cent during the first 20-30 minutes of infusion at $0.5-1.0 \mathrm{ml} / \mathrm{min}$, and then rises slowly as the PVC tubing becomes saturated with NTG. ${ }^{6}$

Intravenous NTG is often infused centrally. Commonly used central venous, and pulmonary arterial catheters contain varying lengths of PVC plastic. We have found in vitro that these catheters cause further significant NTG loss (unpublished data). Until recently, most published clinical investigations of IV NTG have not included detailed descriptions of the NTG delivery systems used, and PVC containers and administration sets were probably employed in many instances. The use of various PVC delivery systems, under a variety of circumstances, probably accounts for the marked variability of IV NTG dosage required to achieve significant haemodynamic effects in these studies.

Recently, reliable commercial non-adsorptive delivery systems for IV NTG (eg. Nitrostat IV, Parke-Davis; Tridilset, American Critical Care) have become available ${ }^{6}$ However, a simple nonadsorptive delivery system can be prepared from materials avaitable in most operating rooms. An infusion pump is used to deliver NTG solution from a glass or polypropylene syringe,* through highdensity polyethylene tubing, $\dagger$ connected to a Teflon catheter $\ddagger$ in a peripheral vein. We have assessed such delivery systems in vitro and found 99 per cent delivery of NTG. Clinical investigations of perioperative IV NTG administration using nonadsorptive delivery systems are now being published. ${ }^{7}$ These studies provide accurate dose response data for nitroglycerin, and suggest that IV NTG is significantly more potent than previously thought. ${ }^{8}$ Thus, inadvertent NTG overdosage may occur if previously published infusion rates for IV NTG are used with non-adsorptive systems. However, with experience, the use of non-adsorptive NTG delivery systems should make IV NTG administration safer, and its effects more predictable. Published investigations of IV NTG

*Plastipak ${ }^{*}$ - Becton Dickinson.

tCobe Laboratories (40/106/001).

‡Cathlon IV ${ }^{\$}$ - Critikon Canada.

From the Department of Anesthesia, St. Boniface General Hospital, University of Manitoba.

Address Correspondence to: Dr. I.R. Thomson, Dept. of Anesthesia, St. Boniface General Hospital, 409 Tache Avenue, Winnipeg, Manitoba, R2H 2 A6. 
should henceforth document that all components of the delivery systems employed were non-adsorptive for NTG.

\section{References}

1 Hill NS, Antman EM, Green LH, Alpert IS. Intravenous nitroglycerin: A review of pharmacology, indications, therapeutic effects and complications. Chest 1981; 79:69-76.

2 Baaske DM, Amann AH, Wagenknecht DM, Carter $J E$, Hoyt HJ, Stoll RG. Nitroglycerin compatibility with incravenous fluid filters, containers and administration sets. Am J Hosp Pharm 1980; 37: $201-5$.

3 Yiken I-H, Derman SL, Sokoloski TD, Burkman LM. Loss of nitroglycerin from aqueous solution into plastic intravenous delivery systems. J Pharm Sci $1979 ; 68: 1163-6$.

4 Cossum PA, Galbraith AJ, Roberts MS, Boyd GW. Loss of nitroglycerin from intravenous infusion sets Lancet 1978; 2: 349-50.

5 Amann AH, Baaske DM. The loss of nitroglycerin from intravenous administration sets during infusion: A theoretical treatment. J Pharm Sci 1982; 71: 473-4.

6 Baaske DM, Amann AH, Kamatz NN et al. Administration set suitable for use with intravenous nitroglycerin. Am J Hosp Pharm 1982; 39: 121-2.

7 Barash PG, Kay H, Geha AS et al. Parenteral nitroglycerin A placebo controlled randomized double blind study. Anesthesiology 1982; 57: A50.

8 Mutch WAC, Culligan JD, Cote DD, Thomson IR. Hemodynamic effects of intravenous nitroglycerin: Importance of the delivery system. Anesth Analg $1982 ; 61: 927-32$. 